\title{
Diabetes mellitus related complications in out- patient clinic of tertiary care hospital
}

\author{
R. Maskey ${ }^{1}$, D.R. Shakya ${ }^{2}$, S.K.Sharma ${ }^{3}$, P. Karki ${ }^{4}$, P. Lavaju ${ }^{5}$ \\ ${ }^{1}$ Assistant Professor, ${ }^{3}$ Professor, ${ }^{4}$ Professor and Head of Department, Department of Internal Medicine, ${ }^{2}$ Associate Professor, \\ Department of Psychiatry, ${ }^{5}$ Associate Professor, Department of Ophthalmology B.P.Koirala Institute of Health Sciences, \\ Dharan, Nepal.
}

\begin{abstract}
We tried to explore the demographic profile and complications of the out patients suffering with Diabetes Mellitus (DM). It was hospital based descriptive study conducted among the 100 diabetic out-patients of B.P.Koirala Institute of Health Sciences, Dharan, Nepal during the period of 1-1-2010 to 29-2-2010. Patients above 14 years diagnosed as per ADA guidelines 2009 giving written informed consent were taken. The number of common diabetes related complications were searched and diagnosed clinically with the use of relevant investigations which included macro-vascular complications like ischemic heart disease, peripheral vascular disease, and micro-vascular complications like diabetic retinopathy, diabetic neuropathy, and diabetic nephropathy. Among 100 confirmed cases of diabetes mellitus (51male and 49 female).Of all diabetes, $99 \%$ were type 2, $1 \%$ were type 1 . About $42 \%$ subjects were of age group between 40-60 yr. When BMI $\geq 23 \mathrm{~kg} / \mathrm{m}^{2}$ (as recommended for Asians) is taken as the determining factor for overweight, $29 \%$ of patients were overweight ,56\% obese and $6 \%$ morbid obese. About $83 \%$ of subjects were on OHA, $9 \%$ on Insulin and $8 \%$ on OHA and insulin both. The most common and frequent chronic complications were neuropathy $(44.4 \%)$ followed by cardiovascular and retinopathy (27.7\%),nephropathy(16.6\%) and others (11.3\%).About $25 \%$ of subjects had hypertension (stage 1 hypertension-17\%, and stage 2 hypertension $8 \%$ ).As most of the patients are overweight with more neurological and cardiovascular complications so the lifestyle changes are required with regular antidiabetics and dietary restriction.
\end{abstract}

Keywords: Diabetes mellitus, complications, outpatients.

\section{Introduction}

Diabetes Mellitus (DM) is one of the most common chronic diseases, with an overall prevalence of approximately $2 \% .^{1}$ International Diabetes Federation (IDF) has estimated 200 million people around world have diabetes and by 2025 it is expected to increase to 333 million and double by

Correspondence: R. Maskey

Email: drmaskey@gmail.com
$2030 .^{2}$ In US, Type1 DM approximately account for $10 \%$ and type $285-90 \%$ of all known cases of DM. ${ }^{3}$ Untreated DM causes much morbidity and mortality due to its devastating late complications involving micro-vascular and macro-vascular structures. ${ }^{4}$ 
Nepal has highest prevalance of prediabetes and among SAARC countries. ${ }^{5}$ Current population census 2001 of Nepal $14.2 \%$ total 23.2 million populations lived in urban. ${ }^{6} \mathrm{DM}$ prevalence among urban subjects are higher than rural ones (urban $25.9 \%$ vs rural $3.1 \%$ ) in Nepal. ${ }^{7}$

The prevalence of diabetes is around 15\% among people aged more than 20 years and $19 \%$ among people aged 40 years and above. ${ }^{7}$ One in ten Nepalese are found to have DM.In a hospital based study done by Karki $P$ et al in BPKIHS, reported DM in $6.3 \% .{ }^{8}$ The main reasons for the diabetes epidemic in Urban Nepal are obviously increased body weight due to high intake of fatty and other food and low physical activity. ${ }^{9}$ Recently Western Health Organisation (WHO) has recommended BMI of 23 as overweight in people of Asian origin, and 25 or above as obese. ${ }^{10}$ The problem of diabetes is reflected by its increasing complications. DM is reported to be leading cause of chronic renal failure in Nepal. ${ }^{11}$

In hospital based exploratory study conducted among the admitted DM patients during the period of 1-3-2003 to 29-2-2004 in medical units in BPKIHS,Nepal. About $50 \%$ of subjects were on Insulin. About $60.7 \%$ subject had hypertension, $39.3 \%$ had ocular problem, and $25 \%$ had renal problems. ${ }^{12}$ It is really time to act by everyone concerned to control the epidemic of diabetes in urban Nepal.

\section{Materials and methods}

It was hospital based descriptive study conducted among the 100 diabetic out-patients during the period of 1-1-2010 to 29-2-2010 at B P Koirala
Institute of Health Sciences, a tertiary referral center in eastern region of Nepal, after getting an approval from the ethical committee.

Patients above 14 years diagnosed as per ADA guidelines 2009 giving written informed conset were enrolled. A thorough physical examination and blood investigations was done to fulfill ADA criteria for DM in all subjects. Socio-demographic profile, information and clinical findings (e.g BMI) about diabetes mellitus and other physical problems was collected and recorded in a semi-structured performa designed for the particular purpose. Height and weight were recorded for body mass index (BMI-weight in $\mathrm{kg} /$ height in $\mathrm{m}$ 2). BMI between 18.5 and 22.9 was considered normal, 23.24.9 as overweight and $>25$ as obese. Hypertension was defined as the presence of systolic BP $>140$ $\mathrm{mm} \mathrm{Hg}$ and diastolic BP of $>90 \mathrm{mmHg}$ or a known hypertensive on treatment. Femoral, popliteal, tibialis posterior and dorsalis pedis arteries were palpated and noted as normal, diminished, absent or leg amputated. Subjects with urinary tract infection, detected by dipstick (multistix), pregnant diabetic women,individuals with a protuberant belly or umbilical hernia and those who did not consent to participate, were excluded.

Diabetes mellitus was diagnosed if survey participants have ever been diagnosed with the condition according to recent ADA guideline 2009.According to the expert committee on the diagnosis and classification of diabetes mellitus $2003^{13}$, diabetes mellitus is diagnosed clinically when a person has: 
R. Maskey et al. Diabetes mellitus related complications in out- patient clinic of tertiary care hospital

1. Fasting Plasma Glucose (FPG) $\geq 126 \mathrm{mg} / \mathrm{dl}(7.0$ $\mathrm{mmol} / \mathrm{l})$. Fasting is defined as no caloric intake for at least $8 \mathrm{~h}$.

\section{OR}

2. Symptoms of hyperglycemia and a casual (random) plasma glucose (RBS) $\geq 200 \mathrm{mg} / \mathrm{dl}$ (11.1 mmol/l). Casual (random) is defined as any time of day without regard to time since last meal. The classic symptoms of hyperglycemia include polyuria, polydipsia, and unexplained weight loss.

\section{OR}

3. 2-h plasma glucose (post-prandial plasma glucose PP) $\geq 200 \mathrm{mg} / \mathrm{dl}(11.1 \mathrm{mmol} / \mathrm{l})$ during an oral glucose tolerance test (OGTT). The test should be performed as described by the World Health Organization using a glucose load containing the equivalent of $75-\mathrm{g}$ anhydrous glucose dissolved in water.*

* In the absence of unequivocal hyperglycemia, these criteria should be confirmed by repeat testing on a different day.

Every patient blood sample was collected for measurement following standard package of diabetes investigations, including: RBS, FPS, PP, serum urea and creatinine, routine urine examination, lipid profile (Total cholesterol, HDL, Triglycerides, LDL, VLDL), serum sodium and potassium, Electrocardiography (ECG), Chest X-ray. A blood sample will be collected for measurement of clinical parameters. Glycosalted Hemoglobin (HbA1c) is evaluated using Immunochromatogaraphy method with NYCO CARD READER II fully automated HbA1c analyzer system.
The number of common diabetes related complications were searched and diagnosed clinically with the use of relevant investigations which included macro-vascular complications like ischemic heart disease, peripheral vascular disease, and microvascular complications like diabetic retinopathy, diabetic neuropathy, and diabetic nephropathy. Sensation was examined using a 10gram Semmes- Weinstein monofilament on the ten recommended sites on plantar and dorsal aspects of feet. The results were documented as normal, diminished, absent or leg amputated. Subjects with diminished or absent sensation were labelled as neuropathic. The knee and ankle reflexes were elicited and noted as normal, diminished, absent or leg amputated. Subjects with diminished or absent knee or ankle reflex or amputation on either limb were labelled as neuropathic.Feet were examined for the presence of callus, healed ulcer or active ulcer. All patients were sent to Ophthalmology OPD for fundus evaluation.Fundal examination was performed by indirect ophthalmoscopy. Microdots, blot haemorrhages and hard and soft exudates were considered as background retinopathy. The presence of new vessels was taken as proliferative retinopathy. Macrovascular complications were defined as history positive for one or more of three conditions: angina, heart attack or stroke. Nephropathy was defined as presence of protein either macroalbumin or microalbumin and absence of pus cells in urine. The creatinine level $<1.2 \mathrm{mg} / \mathrm{dl}$ was taken as normal.

\section{Statistical analysis}

The data was analyzed using Excel and SPSS programme. 


\section{Results}

Fig.1

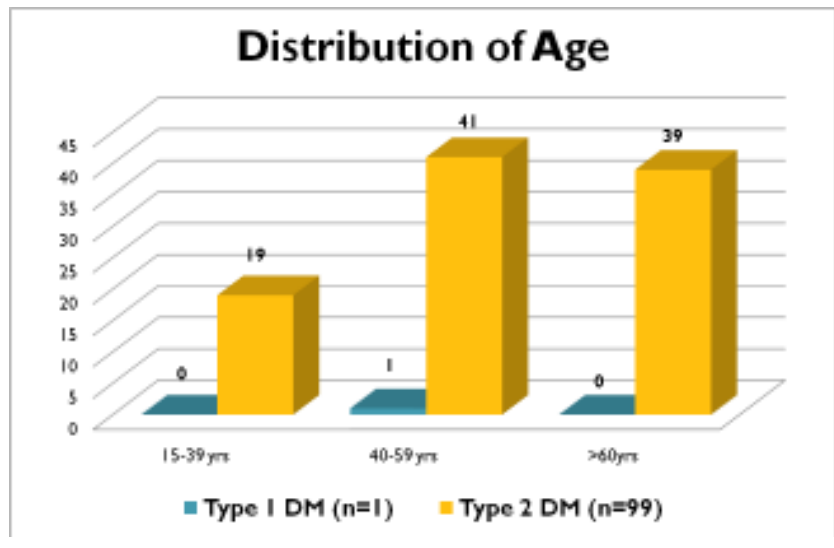

Fig. 2

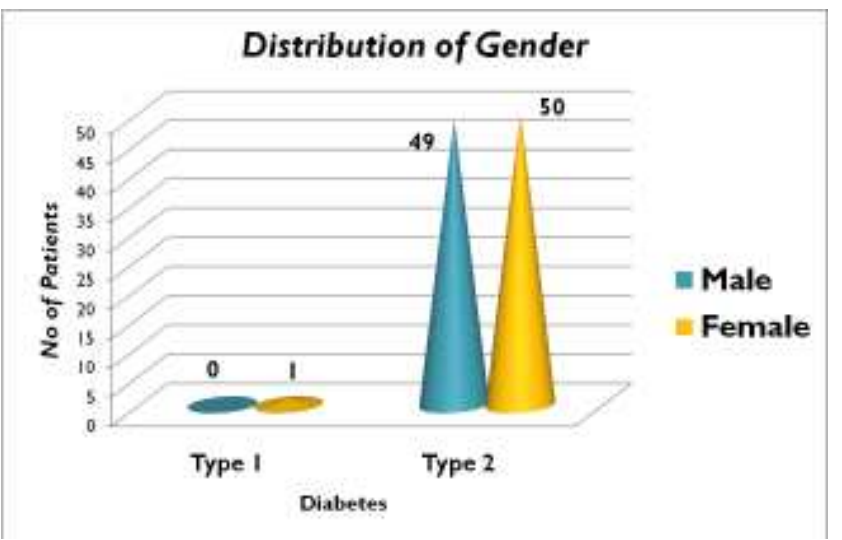

Among 100 confirmed cases of diabetes mellitus (51male and 49 female). Of all diabetes, 99\% were type

2, $1 \%$ were type 1 . About $42 \%$ subjects were of age group between $40-60$ yr. (Fig.1 and Fig.2)

Fig. 3

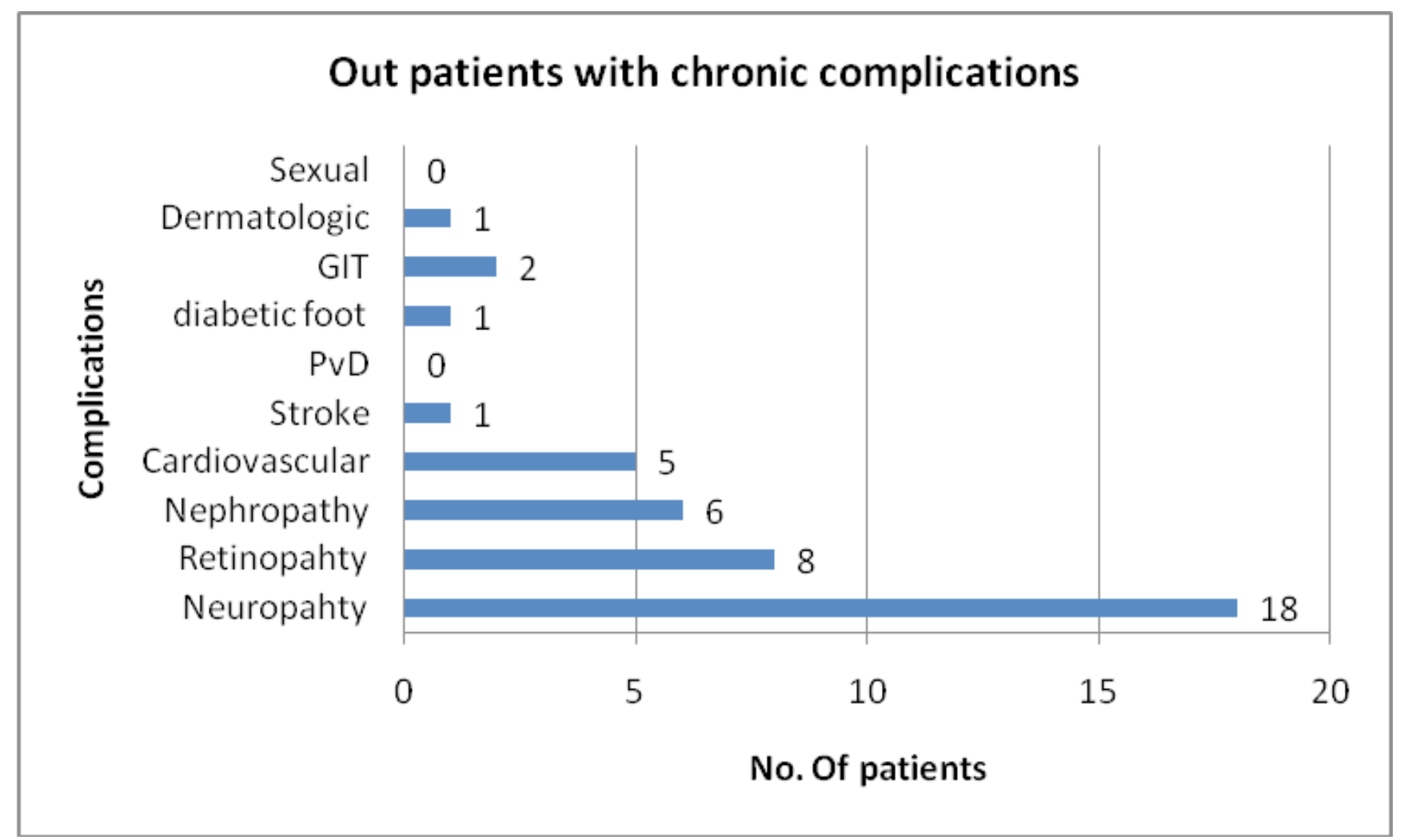

The most common and frequent chronic complications were neuropathy (44.4\%) followed by cardiovascular and retinopathy (27.7\%), nephropathy (16.6\%) and others (11.3\%) (Fig.3) 
R. Maskey et al. Diabetes mellitus related complications in out-patient clinic of tertiary care hospital

Table. 1

\begin{tabular}{lcc}
\hline BMI & Type 1 DM & Type 2 DM \\
\hline Acceptable $(\mathbf{1 8 . 5}-\mathbf{2 2 . 9})$ & 1 & $8(8.08 \%)$ \\
Overweight $\quad(\mathbf{2 3}-\mathbf{2 4 . 9 )}$ & 0 & $29(29.29 \%)$ \\
Obese $(\mathbf{2 5}-\mathbf{2 9 . 9})$ & 0 & $56(56.56 \%)$ \\
Morbidly obese $\quad(\mathbf{3 0})$ & 0 & $6(6.06 \%)$ \\
\hline
\end{tabular}

Table. 2

\begin{tabular}{lcc}
\hline Hypertension & $\begin{array}{c}\text { Type1 DM } \\
(\mathbf{n = 1})\end{array}$ & $\begin{array}{c}\text { Type 2 DM } \\
(\mathbf{n = 9 9})\end{array}$ \\
\hline Pre hypertension & 1 & $74(74.74 \%)$ \\
Stage I & 0 & $17(17.17 \%)$ \\
Stage II & 0 & $18(8.08 \%)$ \\
\hline
\end{tabular}

When BMI $\geq 23 \mathrm{~kg} / \mathrm{m} 2$ (as recommended for Asians) is taken as the determining factor for overweight, $29 \%$ of patients were overweight, $56 \%$ obese and $6 \%$ morbid obese.

Table. 3

\begin{tabular}{lcc}
\hline Duration of DM & Type1 DM & Type 2 DM \\
\hline$\leq$ 5 years & 0 & 55 \\
6- 10 years & 1 & 25 \\
$>$ 10 years & 0 & 19 \\
\hline
\end{tabular}

Fifity five patients with type 2 diabetes were having diabetes since less than 5 years compared to type 1 diabetes.74.74\% of type 2DM had prehypertension followed by $17.17 \%$ and $8.08 \%$ of stage I and stage II hypertension respectively.

Table.4 Micro-vascular complications related to duration of diabetes mellitus

\begin{tabular}{lccc}
\hline Complications & $<$ 5yrs & $\mathbf{5 ~ - ~ 1 0 ~ y r s ~}$ & $>$ 10yrs \\
\hline Neuropathy & $12(66.66 \%)$ & $4(22.22 \%)$ & $2(11.11 \%)$ \\
Retinopathy & $2(25 \%)$ & $2(25 \%)$ & $4(50 \%)$ \\
Nephropahty & $1(16.6 \%)$ & $2(33.3 \%)$ & $3(50 \%)$ \\
\hline
\end{tabular}

When we compared micrvoascular complications related to duration of diabetes mellitus most of the patients had neuropathy $12(66.66 \%)$ during less than 5 years followed by retinopathy $4(50 \%)$ and nephropathy $3(50 \%)$ during more than 10 years of diabetes.

\section{Discussion}

Diabetes mellitus is a very common metabolic and vascular complications of diabetes mellitus had preventable disorder. Micro-vascular complications due to diabetes mellitus are the cause for much morbidity and mortality.In many studies worldwide. statistically significant association among the complications which increases with duration of disease and poor glycemic control. ${ }^{14,15}$

It was documented that macro as well as micro- 
In our study, male was found to be more than female (51 M: 49F) with 42\% subjects were of age group between 40-60 yr which was similar to study done in Taiwan in 1998 among 558 patients (293 men and 265 women, aged $61.4+/-10.0 \mathrm{yr}$ ) with noninsulin-dependent diabetes mellitus. ${ }^{16}$

The most common complication was neuropathy (44.4\%) in our study which is higher than the Indian results (27.5\%). ${ }^{17}$ The reason could be neuropathy is often ignored due to insidious onset and slow progress. We had retinopathy (27.7\%), nephropathy (16.6\%) and others (11.3\%).The high figures of retinopathy in our population could be attributed to a lack of awareness in our patients to undertake regular eye examination.

The prevalence of obesity in our results was $56 \%$ with BMI above $(>27 \mathrm{~kg} / \mathrm{m} 2)$ which was similar as Haider et al ${ }^{18}$ reported $56 \%$ of 500 subjects with essential hypertension to be obese as measured by the Ponderal Index. This emphasizes the importance of routine measurement of WHR which is we have not done and is major limitation of our study. For Asian population, there is perhaps a need for lower BMI indices as cut levels for obesity. Because according to a cross-sectional survey among government employees in five urban Nepalese districts linked lifestyle to obesity; one third of the employees were overweight or obese. ${ }^{19}$ Increased age, marital status, higher education, greater job responsibilities, increased alcohol consumption, and motorized transport all associate significantly with obesity. Taken together, these studies suggest that urbanization is the major driving force behind obesity in Nepal.
We had type 2 diabetes patients having diabetes since less than 5 years more as compared to type 1 diabetes.74.74\% of type 2DM had prehypertension followed by $17.17 \%$ and $8.08 \%$ of stage I and stage II hypertension respectively. When we compared micrvoascular complications related to duration of diabetes mellitus most of the patients had neuropathy $12(66.66 \%)$ during less than 5 years followed by retinopathy 4(50\%) and nephropathy $3(50 \%)$ during more than 10 years of diabetes which was similar to study done by K. N. Yogi in Nepal. ${ }^{20}$

Our study concluded that the prevalence of diabetic microvascular complications was higher in people with poor glycaemic control, longer duration of diabetes associated hypertension and obesity. We recommend screening of high risk groups and emphasize importance of early diagnosis of diabetes and detection of chronic complications so that appropriate treatment initiated at the earliest.

\section{Conclusion}

Diabetes Mellitus is associated with many complications. Neuropathy, retinopathy, nephropathy and cardiovascular complications were more frequently seen. Obesity was seen in $56 \%$ of patients. Life style modification is essential for better life. So I would suggest all diabetic patients to follow IDF slogan "Walk More and Eat Less" for preventing diabetes.

\section{Acknowledgement}

We wish to express our gratitude to Dr. S.K. Sharma, Dr. P. Karki, Dr. D.R. Shakya and Dr. Poonam Lavaju for their support and 
R. Maskey et al. Diabetes mellitus related complications in out- patient clinic of tertiary care hospital

encouragement. I would also thanks Dr. D.D. Baral for helping me in statistical analysis.

\section{References}

1. P. Zimmet. Type-2 DM an Epidemiological overview.Diabetologia 1982 (22):399-4.

2. International Diabetes Digest.Cambridge: FSG Communications Limited \& International Diabetes Federation, 1995; 6 (4):87-8.

3. S.C. Smelter, B.G. Bare. Text book of Medical-Surgical Nursing Lippincott,United Kingdom , $8^{\text {the }}$ di. 1996.

4. A.A. John. Hunter, Davidson's Principles and Practice of Medicine, Churchill Livingstone, 20th Edi. 2002.

5. F. White, G. Rafique. Diabetes prevalence and projections in South Asia. Lancet 2002; 360 (93):804-5.

6. G.P. Koirala. Demographics dynamics changing consumption pattern, poverty, agriculture and rural development,role of farmers in sustainable development,sectoral reports on sustainable development agenda for Nepal(SDAN).[online].2002[cited 2009 june 25].Available from:http://www.scdp.org.np/sdan/ SDANrpt1.pdf.

7. D.L. Singh, M.D. Bhattrai. High prevalence of diabetes and impaired fasting glycemia in urban Nepal (letter).Diabet. Med. 2003; 20(2):170-1

8. P. Karki, N. Baral, M. Lamsal et al. Prevalence of noninsulindependent diabetes mellitus in urban areas of eastern Nepal:a hospital based study. South East Asian J Tropical Med Public Helath, 2000; 31(1):163-6.

9. D.L. Singh, M.D. Bhattarai, A. Maskey A. Demographic profile of diabetic patients admitted in medical wards of Bir Hospital,Nepal, 1990 to 1994.
10. WHO expert consultation. Appropriate BodyMass Index for Asian populations and its implications for policy and intervention strategies. Lancet 2004; 363: 157-63.

11. P.R. Satyal. Evolution of nephrology in Nepal. Souvenir: $1^{\text {st }}$ International CME Programme of Nepal Society of Nephrology, 13 October 1998, Kathmandu, Nepal: 1-4.

12. R.S. Mehta, P. Karki, S.K. Sharma. Risk factors, associated health problems, reasons for admission and knowledge profile of diabetes patients admitted in BPKIHS. Kathmandu University Medical Journal 2006; 4(1):11-3.

13. Expert committee on diagnosis and classification of Diabetes Mellitus: Diabetes Care 2003; 23 (suppl.1); S4-S19.

14. United Kingdom Prospective Diabetes Study: Intensive blood glucose control with sulphonylurea or insulin compared with conventional treatment and risk of complictions in type 2 diabetes (UK PDS-33) Lancet. $1998 ;$ 352-837.

15. D.M. Nathan, D.E. Singer, J.E. Godine et al. Smilar frequency of retinopathy in IDDM and NIDDM.Retinopathy in older NIDDM diabetics.Association with glucose control. Diabetes 1986;35:797-901.

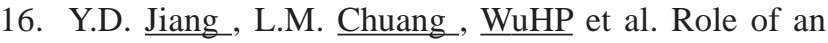
outpatient clinic in screening chronic complications of diabetes: a model for diabetes managed care. $\underline{\mathrm{J} \text { Formos }}$ Med Assoc. 1998;97(8):521-7.

17 A. Ramachandran, C. Snehalatha, K. Satyavani, et al Prevalence of complications and their risk factors in type 2 diabetes.J Assoc Physicians India 1999;47:1152-6.

18. Z. Haider, K.A. Bano. Prevalence of obesity in patients with essential hypertension of varying severity $\mathrm{J} P a k$ Med assoc 1985; 35354-7 
Journal of College of Medical Sciences-Nepal,2011, Vol-7,No-2

19. P. Simkhada, A. Poobalan, P.P. Simkhada et al. Knowledge, attitude, and prevalence of overweight and obesity among civil servants in Nepal. Asia Pac. J. Public Health 2009, Oct 12 [Epub ahead of print].
20. K. N. Yogi. Micro-vascular complication in diabetic patient's of type -2 diabetes mellitus. Journal of Institute of Medicine, December, 2008; (3) 49-58. 